\title{
A Low-Cost High-Temperature Sensor Based on Long-Period Fiber/Microfiber Gratings by Local Fictive Temperature Modification
}

\author{
Guorui Zhou, ${ }_{1}^{1}$ Chuanchao Zhang ${ }^{D},{ }^{1}$ Xiufang Xie, ${ }^{2}$ Yi Wan, ${ }^{3}$ Caizhen Yao $\mathbb{D},{ }^{1}$ Jun Liu, ${ }^{2}$ \\ Longfei Niu, ${ }^{1}$ Xinxiang Miao $₫{ }^{1}{ }^{1}$ Hai Zhou, ${ }^{1}$ Xiaodong Jiang, ${ }^{1}$ Shizhen Xu $₫{ }^{3}$, \\ and Haibing $\mathbf{L v}$ (D) $^{1}$ \\ ${ }^{1}$ Laser Fusion Research Center, China Academy of Engineering Physics, Mianyang 621900, China \\ ${ }^{2}$ Institute of Applied Electronics, China Academy of Engineering Physics, Mianyang 621900, China \\ ${ }^{3}$ School of Physics, University of Electronic Science and Technology of China, Chengdu 610054, China \\ Correspondence should be addressed to Shizhen Xu; xusz@uestc.edu.cn and Haibing Lv; haibinglv@163.com
}

Received 2 March 2020; Accepted 12 May 2020; Published 11 June 2020

Guest Editor: Zhen He

Copyright ( 2020 Guorui Zhou et al. This is an open access article distributed under the Creative Commons Attribution License, which permits unrestricted use, distribution, and reproduction in any medium, provided the original work is properly cited.

\begin{abstract}
A high temperature-sensitive long-period fiber grating (LPFG) sensor fabricated by the local fictive temperature modification is proposed and demonstrated. High-frequency $\mathrm{CO}_{2}$ laser pulses scan standard single-mode fiber (SMF), and the modification zones extended to the core of SMF. Experimental results demonstrate that the LPFG temperature sensors with $600 \mu \mathrm{m}$ grating period and 32 period numbers offer the average sensitivity of $0.084 \mathrm{~nm} / \mathrm{C}$ in the temperature range of room temperature $(\mathrm{RM})$ to $875^{\circ} \mathrm{C}$. The LPFGs fabricated here show exponential change in terms of the spectral wavelength shift versus changes in temperature. In addition, the maximum temperature sensitivity of $0.37 \mathrm{~nm} / \mathrm{C}$ is achieved by employing long-period microfiber grating (LPMFG), fabricated by the microheater brushing technique and the local fictive temperature modification. LPMFG sensor exhibits better temperature characteristics due to a thinner diameter.
\end{abstract}

\section{Introduction}

Compared with conventional electronic sensors, fiber sensors have useful advantages such as their small volume, high sensitivity, fast response, resistance to electromagnetic field interference, and the potential for remote operation [1], which have attracted more and more attention in sensing fields, including monitoring temperature [2], refractive index [3], strain [4], and viruses [5]. The measurement of temperature has great significance in the application fields of industry, scientific research, and clinical medical. For decades, various temperature sensing methods based on optical fiber structure have been proposed and demonstrated, such as Fabry-Perot interferometers [6-8], Mach-Zehnder interferometers [9-11], Sagnac [12-14], fiber Bragg gratings [15-17], and longperiod fiber gratings (LPFGs) [18-23].
LPFGs with a typical period of hundreds of micrometers provide a suitable method for a number of sensing and communication applications, due to its ease of fabrication, low insertion loss, and higher temperature sensitivity. Among the different techniques available to fabricate gratings, fictive temperature modification different from the traditional point-to point technique is a novel method. The interest of the scientific community results from well establishment and ultra-short fabrication time besides enabling the fabrication gratings in any kind of fiber [24]. Fictive temperature modification is a powerful method for topography formation on fiber. Texture on the surface of fiber can be directly realized via the rapid timescales of heating and cooling of fiber by laser pulses with proper energy [25]. In this work, we demonstrate LPFG temperature sensors in the range of room temperature $(\mathrm{RM})-875^{\circ} \mathrm{C}$ fabricated by the local fictive temperature modification via 
high-frequency $\mathrm{CO}_{2}$ laser pulses. Inexpensive standard single-mode fiber (SMF-28) is employed as material for long-period gratings fabrication, and the fabrication time of the temperature sensors proposed is less than $1 \mathrm{~s}$. The experiments show that the temperature sensitivity of the proposed sensor could be effectively improved by fabricating the long-period microfiber gratings (LPMFGs). The maximum temperature sensitivity of the LPMFGs sensors with 32 period numbers and $600 \mu \mathrm{m}$ grating period can reach $0.37 \mathrm{~nm} / \mathrm{C}$, which is 4 times higher than that of LPFG sensors, in the range of $30^{\circ} \mathrm{C}$ to $80^{\circ} \mathrm{C}$.

\section{Theoretical Analysis}

The LPFGs can couple the core mode to the forward propagating cladding modes. The resonant wavelength is determined by the phase matching condition as follows:

$$
\lambda_{m}=\left(n_{\mathrm{eff}}^{\text {core }}-n_{\mathrm{eff}}^{\text {clad }, m}\right) \Lambda,
$$

where $\lambda_{m}$ is the $m$ th-order resonant wavelength at which light propagation in the core mode is coupled to the $\mathrm{LP}_{0 m}$ cladding mode, $m=1,2,3,4, \ldots n_{\mathrm{eff}}^{\text {core }} ; n_{\mathrm{eff}}^{\text {clad, } m}$ and $\Lambda$ represent effective refractive indices of core mode and the $m$ th cladding mode and the grating period, respectively.

When the ambient temperature has changed, the effective refractive index of core and cladding will change. The LPFG material temperature expansion leads to the change in the grating period. The temperature sensitivity can be obtained by the chain-rule differentiation of equation (1) with respect to ambient temperature $T$. The dependence of resonance wavelength against temperature can be written as

$$
\frac{\mathrm{d} \lambda_{m}}{\mathrm{~d} T}=\frac{\mathrm{d}\left(n_{\text {eff }}^{\text {core }}-n_{\text {eff }}^{\text {clad }, m}\right)}{\mathrm{d} T} \cdot \Lambda+\left(n_{\text {eff }}^{\text {core }}-n_{\text {eff }}^{\text {clad }, m}\right) \frac{d \Lambda}{\mathrm{d} T} .
$$

The first term on right hand side of equation (2) is contributed to relative thermal dependence of effective indices of the core and cladding. It defines $\mathrm{d} n^{\text {core }} / T$ and $\mathrm{d} n^{\text {clad }} / T$ as the core and cladding thermo-optic coefficients, respectively. For the proposed LPFGs sensors, the core and cladding with positive thermo-optic coefficients are considered.

\section{Experiments and Results}

Figure 1 illustrates the configuration of an experimental system used for fabricating LPFGs by local fictive temperature modification via high-frequency $\mathrm{CO}_{2}$ laser pulses. Semiconductor laser diode (SLD, Thorlabs, S5FC1550P-A2) used as the light source with a center wavelength of $1550 \mathrm{~nm}$ was connected to SMF-28 as the input port of LPFGs, and the output port of the LPFGs was connected to the optical spectrum analyzer (OSA) (Yokogawa, $6370^{\circ} \mathrm{C}$ ) to ensure successful fabrication of LPFGs. The fabrication of LPFGs by the local fictive temperature modification was performed in a two-step process. Firstly, SMF-28 fixed on two-dimensional translation stages was adjusted to the center of camera field of view using online monitoring system as a component of the local fabrication system. The local fabrication system mainly consists of online monitoring system, two-dimensional translation stages, two-dimensional vibration mirrors, and a commercial $\mathrm{CO}_{2}$ laser with a Gaussian beam and maximum output power of $100 \mathrm{~W}$ operated at $1 \mathrm{kHz}$ with a $25 \%$ duty factor. Secondly, 32 periods and the grating period of $600 \mu \mathrm{m}$ patterns of LPFGs were designed by controlling software in order to obtain the required parameters. Based on equation (1), the grating period was selected to be $\Lambda=600 \mu \mathrm{m}$ so as to work on the effective wavelength region of the SLD source used in the experiment. The SMF-28 samples were moved to focus rectangular $\mathrm{CO}_{2}$ laser irradiation zones. The laser beam was scanned by two-dimensional vibration mirrors, and the laser raster scanning was used to produce hexagonally or orthogonal modification zones according to the designed pattern to form LPFGs in this step. Due to the strong performance of two-dimensional vibration mirrors, the fabrication time of LPFGs was less $1 \mathrm{~s}$.

Figure 2 shows morphologies of the fabricated LPFGs by the local fictive temperature modification. The surface of morphology of LPFGs was obtained by Leica optical microscope with polarization function (Leica, DM2500). The grating period and the period number were $600 \mu \mathrm{m}$ and 32, respectively. The fabricated LPFGs appeared very uniform, and the saddle-shaped grooves were carved by $\mathrm{CO}_{2}$ laser pulses along the fiber axis, as shown in Figure 2. The modification zones of refractive index extended to the core of SMF-28 gradually to form the modulation of input light.

The free-standing fabricated LPFGs could be affected by environmental factors including physical vibration and bending due to its high sensitivity characteristics. Simply equipped LPFGs is essential using a low RI UV curable polymer (Thorlabs) to avoid disturbance in experimental processes influencing sensing results. In brief, two sides of a microscope slide were covered with two regular slides in parallel to create a sensing region. Then, other two smaller slides were fixed in the center of two regular slides to support the LPFGs sample in place. UV curable polymer used to fix the samples was exposed under UV radiation (UV LED system, Thorlabs) for $30 \mathrm{~s}$.

The schematic diagram of the temperature sensing experimental setup is illustrated in Figure 3. SLD source and the OSA used were the same as the ones for LPFG fabrication. The transmission spectra of the LPFGs were measured at different temperatures for the grating region ranging from $\mathrm{RM}$ to $875^{\circ} \mathrm{C}$. The high temperature environment was provided by the microheater (NTT-AT, CMH7019) driven by a tunable DC power supply. The grating region of LPFGs was inserted into the center of the slot of the microheater whose length was enough to cover the entire grating region. The temperature environment increased by increasing the current of the power supply from 0 to $3.5 \mathrm{~A}$ with intervals of $0.1 \mathrm{~A}$. Every temperature environment was kept constant for 10 minutes to ensure a stable temperature distribution in the microheater.

The transmission spectra were recorded at different temperatures. The relationship between the current and the temperature in the microheater was provided by the manufacturer of the heater. 


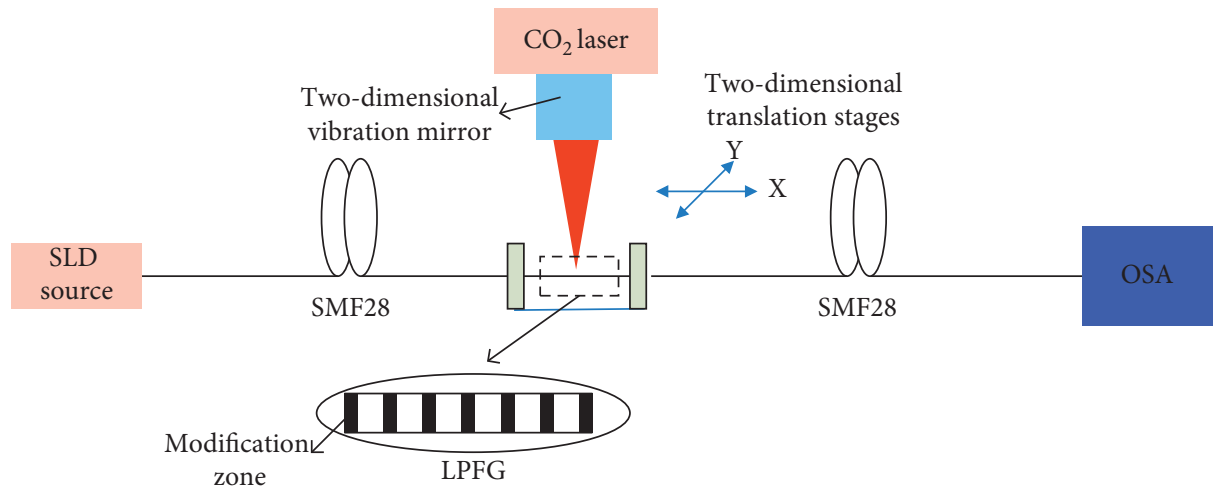

FIgURE 1: The fabrication setup of LPFGs by local fictive temperature modification via $\mathrm{CO}_{2}$ laser.

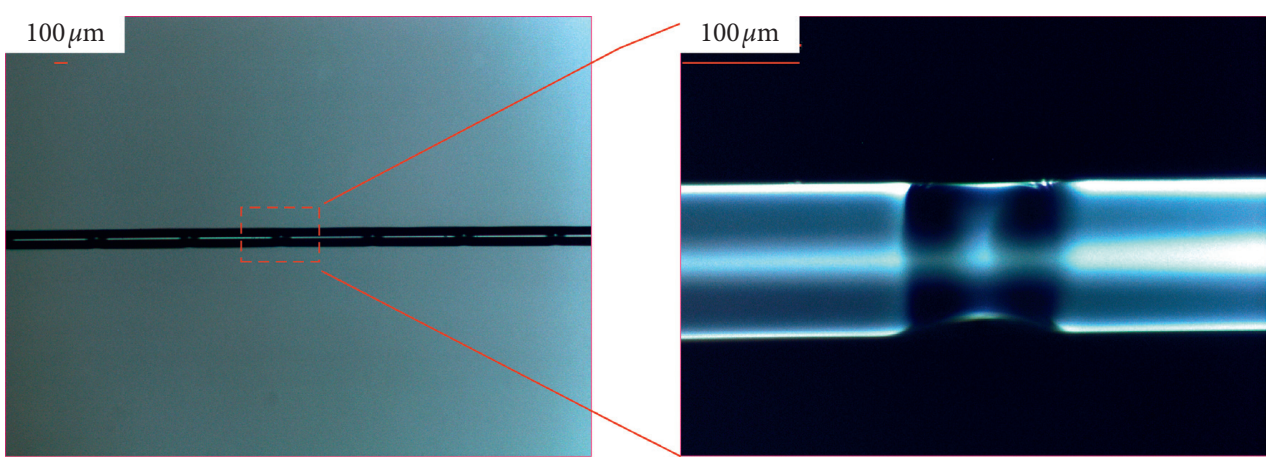

FIGURE 2: The surface morphologies of the fabricated LPFGs.

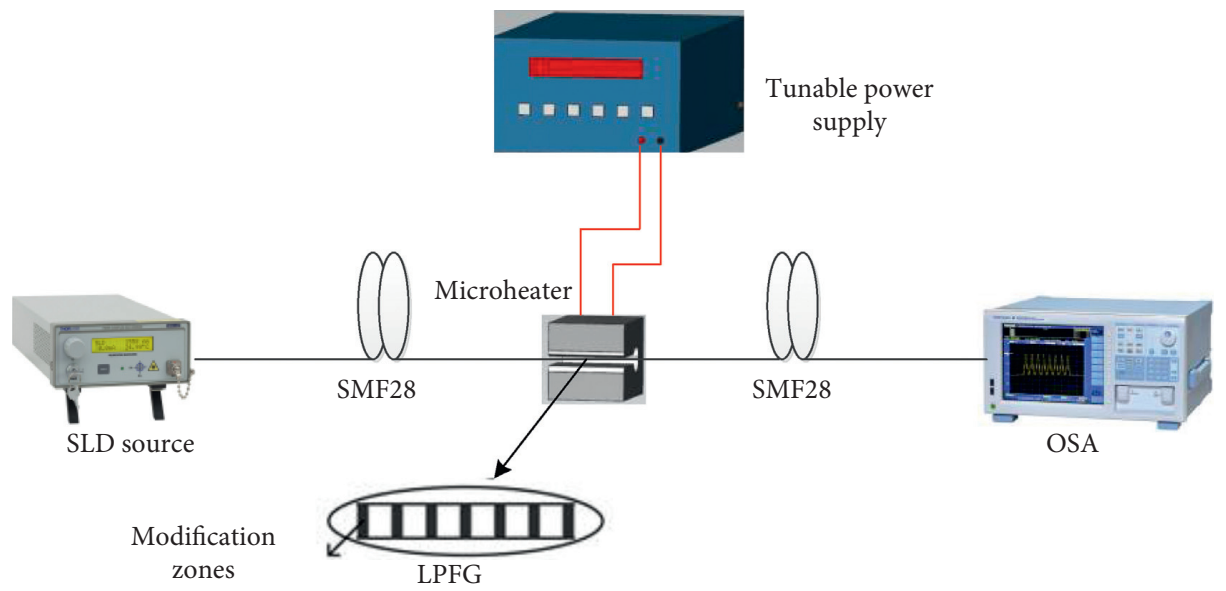

FIGURE 3: The schematic diagram of the temperature sensing experimental setup.

Figure 4(a) illustrates measured spectral responses at different temperatures ranging from $\mathrm{RM}$ to $875^{\circ} \mathrm{C}$ with intervals of $125^{\circ} \mathrm{C}$. When the temperature environment increased, the selected dip wavelength of the spectrum experienced a redshift with the measured temperature range. These shifts correspond to a temperature-induced spectral shift of about $71.36 \mathrm{~nm}$ during the entire measurement process. To obtain the exact relationship between temperature environments and dip wavelength shift, a finer temperature variation experiment was adopted. Figure 4(b) shows the relationship between temperature environment and dip wavelength shift over the temperature ranging from $\mathrm{RM}$ to $875^{\circ} \mathrm{C}$ by heating the LPFG sensors in $25^{\circ} \mathrm{C}$ steps. The average sensitivity $0.084 \mathrm{~nm} / \mathrm{C}$ was achieved. The solid line in the figure was the exponential fit of the experimental results, which indicated that LPFG sensors have exhibited a higher sensitivity in the higher temperature range. Moreover, the performance of our LPFG temperature sensor in the cooling process has also been investigated, as shown in Figure 4(b). From the figure, it is clear that they have almost 


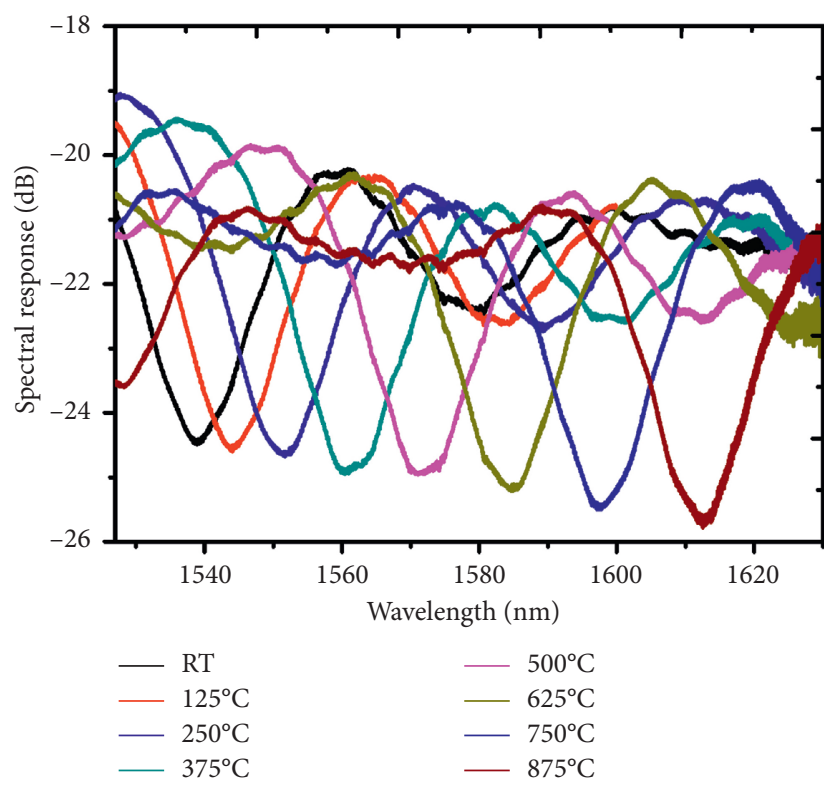

(a)

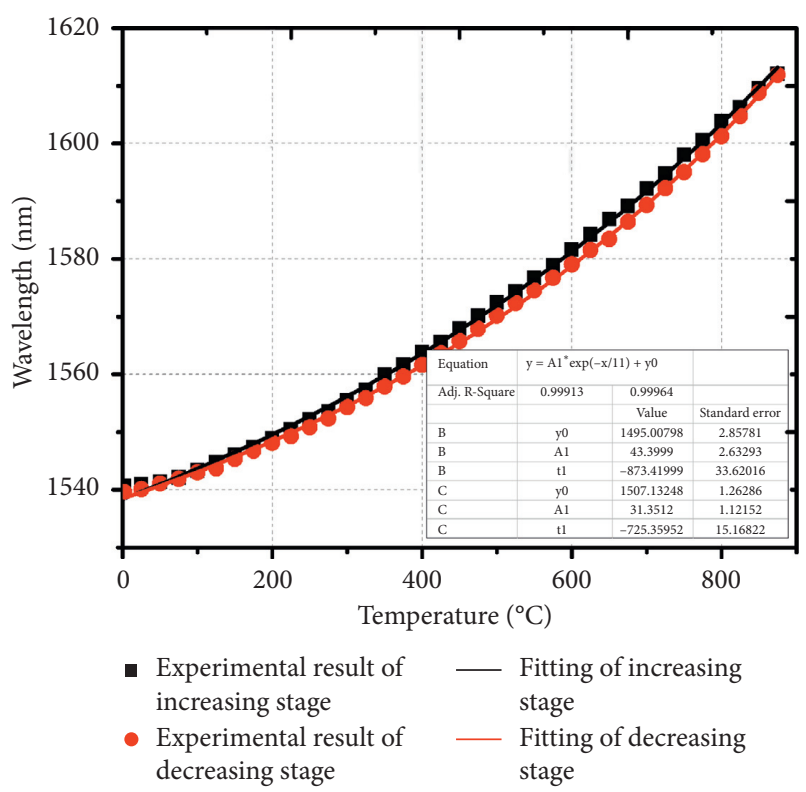

(b)

FIGURE 4: (a) Measured spectral responses at different temperatures ranging from $\mathrm{RM}$ to $875^{\circ} \mathrm{C}$ with intervals of $125^{\circ} \mathrm{C}$; (b) the relationship between corresponding dip wavelength shifts and the temperature.

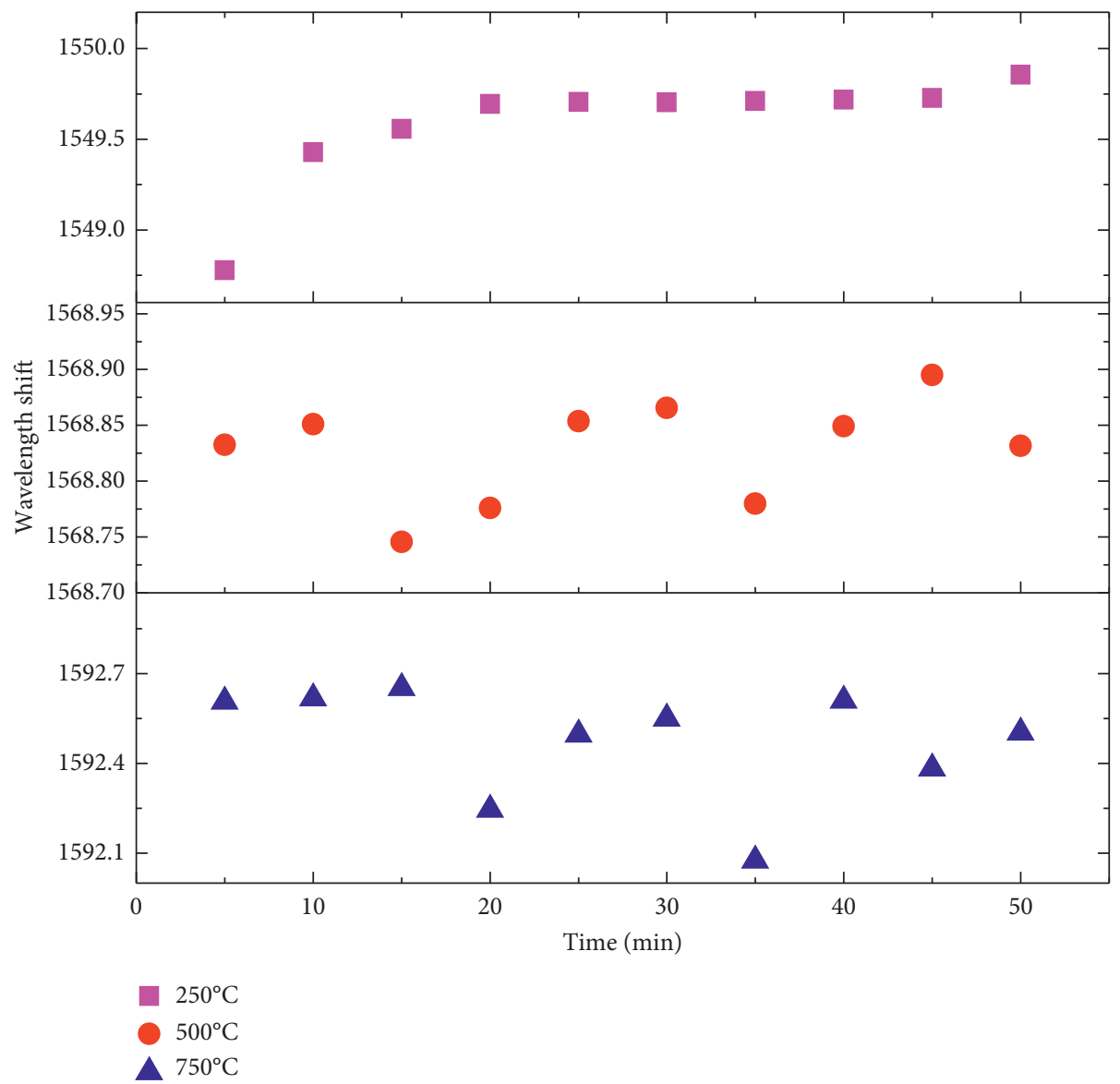

FIgURE 5: Signal changes with measurement time increasing at $250^{\circ} \mathrm{C}, 500^{\circ} \mathrm{C}$, and $750^{\circ} \mathrm{C}$. 


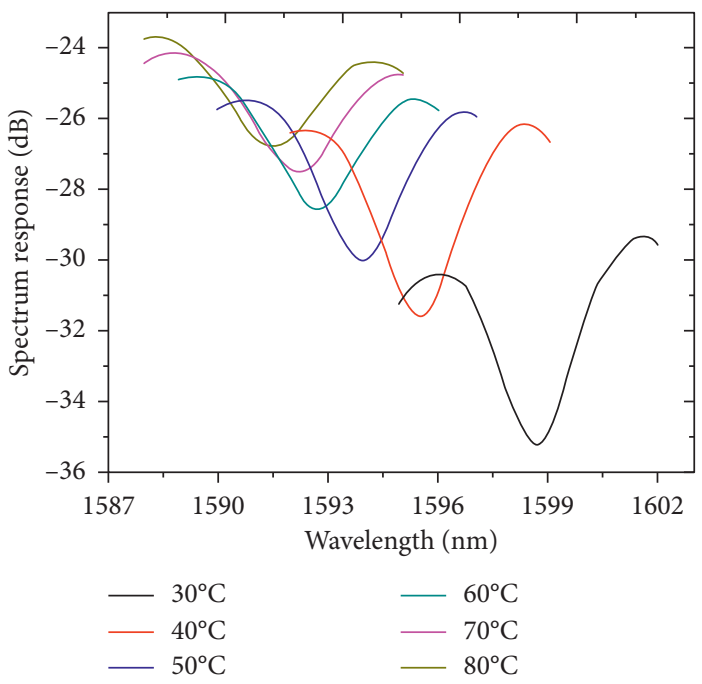

(a)

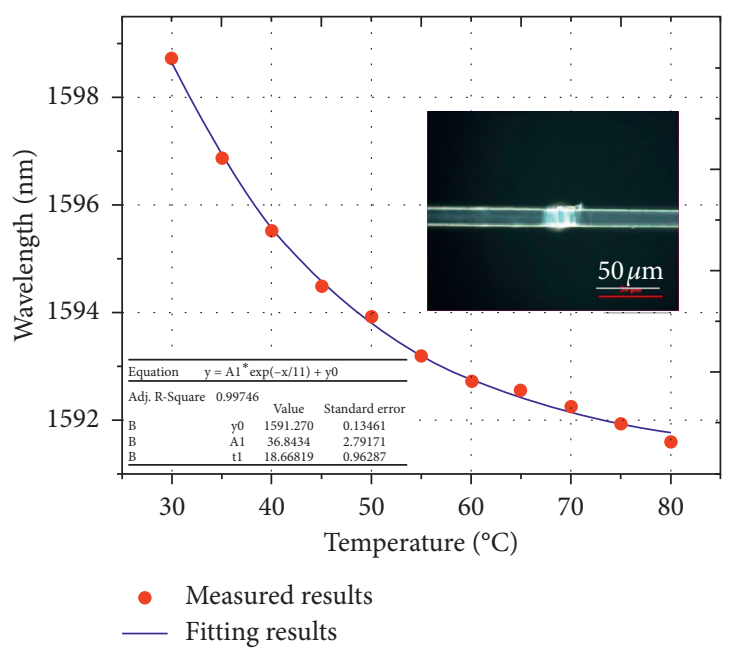

(b)

Figure 6: (a) Transmission spectrum of LPMFGs at different temperatures ranging from $30^{\circ} \mathrm{C}$ to $80^{\circ} \mathrm{C}$; (b) corresponding relationships between temperature and the dip wavelength shift and the optical microscope image of modification zone of fabricated LPMFGs as shown in the inset.

the same exponential dependence on the temperature. The fit of the experimental data gave a sensitivity of about $0.085 \mathrm{~nm} / \mathrm{C}$. The different temperature sensitivity numbers result from the different temperature distribution during heating and cooling processes.

In order to investigate the stability of our LPFG temperature sensors in high temperature environment, signal changes with measurement time increasing at $250^{\circ} \mathrm{C}, 500^{\circ} \mathrm{C}$, and $750^{\circ} \mathrm{C}$ are shown in Figure 5. Measured spectral responses during 50 minutes were recorded every 5 minutes. The redshift standard deviation of $0.54 \mathrm{~nm}$ at $250^{\circ} \mathrm{C}$ is larger than that of $500^{\circ} \mathrm{C}$ and $750^{\circ} \mathrm{C}$, while the redshift standard deviation of $0.07 \mathrm{~nm}$ at $500^{\circ} \mathrm{C}$ is smaller than that of $250^{\circ} \mathrm{C}$ and $750^{\circ} \mathrm{C}$. It believes that the discrepancy in dip wavelength shift at the same temperature mainly results from the limited precision in microheater heating controlling. We have reason to believe that LPFGs fabricated by local fictive temperature modification have excellent stability in the entire measurement process, and there is no stability performance degradation in high temperature environment.

As far as we know, reducing the diameter of LPFGs might result in a higher sensitivity. Hence, it is necessary to demonstrate temperature dependence of LPMFGs. In the experiment, microfibers with about $11 \mu \mathrm{m}$ diameter were fabricated based on the taper drawing system using the microheater brushing technique. The fabrication and package process of LPMFGs were the same as that of the LPFGs. Considering more fragile mechanical stability, the fabricated LPMFGs were put into an airtight container with the function of precise control of temperature to measure the temperature dependence. The SLD source and OSA used were the same as the ones used for LPFG sensing. The transmission spectra of LPMFGs, as shown in Figure 6(a), were measured at different temperatures ranging from $30^{\circ} \mathrm{C}$ to $80^{\circ} \mathrm{C}$. It was observed that, as the temperature increased from $30^{\circ} \mathrm{C}$ to $80^{\circ} \mathrm{C}$, the central wavelength of the spectral dip shifted to a shorter wavelength monotonically. The wavelength shifts versus temperature is clearly plotted in Figure 6(b). The modification zone of the fabricated LPMFGs can be observed in the inset of Figure 6(b). It is clear that wavelength shift changed exponentially with the increase in the temperature, from $30^{\circ} \mathrm{C}$ to $80^{\circ} \mathrm{C}$. The total wavelength shifted from $30^{\circ} \mathrm{C}$ to $80^{\circ} \mathrm{C}$ was $7.1 \mathrm{~nm}$, and the maximum sensitivity of $0.37 \mathrm{~nm} / \mathrm{C}$ was achieved in the temperature range of $30^{\circ} \mathrm{C}$ to $35^{\circ} \mathrm{C}$. The temperature sensitivity achieved in this experiment is 4 times higher than that of the LPFG temperature sensor. From the experimental results, the LPFGs fabricated by the local fictive temperature modification can be applied to the high temperature environment, but the LPMFGs are skilled in sensing of low temperature. Therefore, the parallel connection of the two methods can be used to realize the temperature sensing to ensure the measurement accuracy of low temperature.

\section{Conclusion}

In the work, a high temperature sensor based on LPFG fabricated by the local fictive temperature modification is demonstrated. Compared with LPFGs fabricated by other methods, the LPFGs demonstrated in the work provide a lower cost, shorter fabrication time, and wider temperature range. The sensor has an average temperature sensitivity of $0.084 \mathrm{~nm} / \mathrm{C}$ in the range of $\mathrm{RM}-875^{\circ} \mathrm{C}$ by exponential fitting, while the maximum temperature sensitivity of LPMFGs is $0.37 \mathrm{~nm} / \mathrm{C}$. Moreover, the reason why the temperature sensitivity of LPMFGs can be enhanced is mainly due to the thinner diameter with thermo-optic effect. The high temperature sensor with compact structure and high sensitivity can be applicable to some structure health monitoring and material processing, electrical transformer, petroleum pipeline, and so on. 


\section{Data Availability}

The datasets generated during and/or analysed during the current study are available from the corresponding author on reasonable request.

\section{Conflicts of Interest}

The authors declare that they have no conflicts of interest.

\section{Acknowledgments}

The work was supported by the National Natural Science Foundation of China (Grant nos. 51535003, 61605186, and 61705205) and Laser Fusion Research Center Funds for Young Talents (Grant no. RCFPD1-2017-7).

\section{References}

[1] O. S. Wolfbeis, "Fiber-optic chemical sensors and biosensors," Analytical Chemistry, vol. 80, no. 12, pp. 4269-4283, 2008.

[2] L. V. Nguyen, D. Hwang, S. Moon, D. S. Moon, and Y. Chung, "High temperature fiber sensor with high sensitivity based on core diameter mismatch," Optics Express, vol. 16, no. 15, pp. 11369-11375, 2008.

[3] W. Liang, Y. Huang, Y. Xu, R. K. Lee, and A. Yariv, "Highly sensitive fiber Bragg grating refractive index sensors," Applied Physics Letters, vol. 86, no. 15, Article ID 151122, 2005.

[4] X. Dong, H. Du, X. Sun, Z. Luo, and J. A. Duan, "A novel strain sensor with large measurement range based on all fiber Mach-Zehnder interferometer," Sensors, vol. 18, no. 5, p. 1549, 2018.

[5] M. Janczuk-Richter, M. Dominik, E. Roźniecka et al., "Longperiod fiber grating sensor for detection of viruses," Sensors and Actuators B: Chemical, vol. 250, pp. 32-38, 2017.

[6] G. Zhang, X. Wu, S. Li et al., "Miniaturized Fabry-Perot probe utilizing PMPCF for high temperature measurement," $A p$ plied Optics, vol. 59, no. 3, pp. 873-877, 2020.

[7] X. L. Cui, H. Zhang, and D. N. Wang, "Parallel structured optical fiber in-line Fabry-Perot interferometers for high temperature sensing," Optics Letters, vol. 45, no. 3, pp. 726729, 2020.

[8] T. T. Salunkhe, D. J. Lee, H. K. Lee, H. W. Choi, S. J. Park, and I. T. Kim, "Enhancing temperature sensitivity of the fabryperot interferometer sensor with optimization of the coating thickness of polystyrene," Sensors, vol. 20, no. 3, p. 794, 2020.

[9] T. Liu, J. Wang, Y. Liao, X. Wang, and S. Wang, "All-fiber Mach-Zehnder interferometer for tunable two quasi-continuous points' temperature sensing in seawater," Optics Express, vol. 26, no. 9, pp. 12277-12290, 2018.

[10] S.-N. Wang, R.-Q. Lv, Y. Zhao, and J.-K. Qian, "A machzehnder interferometer-based high sensitivity temperature sensor for human body monitoring," Optical Fiber Technology, vol. 45, no. 9, pp. 93-97, 2018.

[11] F. Zhang, X. Xu, J. He, B. Du, and Y. Wang, "Highly sensitive temperature sensor based on a polymer-infiltrated MachZehnder interferometer created in graded index fiber," Optics Letters, vol. 44, no. 10, pp. 2466-2469, 2019.

[12] J. Shi, Y. Wang, D. Xu et al., "Temperature sensor based on fiber ring laser with Sagnac loop," IEEE Photonics Technology Letters, vol. 28, no. 7, pp. 794-797, 2016.

[13] L. Liu, H. Gao, T. Ning et al., "High accuracy temperature sensing system exploiting a Sagnac interferometer and an optoelectronic oscillator," Optics \& Laser Technology, vol. 123, Article ID 105951, 2020.

[14] G. Wang, Y. Lu, X. Yang, L. Duan, and J. Yao, "Square-lattice alcohol-filled photonic crystal fiber temperature sensor based on a Sagnac interferometer," Applied Optics, vol. 58, no. 8, pp. 2132-2136, 2019.

[15] P. Cheng, L. Wang, Y. Pan et al., "Fiber Bragg grating temperature sensor of cladding with $\mathrm{SrTiO}_{3}$ thin film by pulsed laser deposition," Laser Physics, vol. 29, no. 2, Article ID 025107, 2019.

[16] P. Zhu, J. Wu, M. Huang, Y. Wang, P. Liu, and M. A. Soto, "Reducing residual strain in fiber bragg grating temperature sensors embedded in carbon fiber reinforced polymers," Journal of Lightwave Technology, vol. 37, no. 18, pp. 46504656, 2019.

[17] A. Arora, M. Esmaeelpour, M. Bernier, and M. J. F. Digonnet, "High-resolution slow-light fiber Bragg grating temperature sensor with phase-sensitive detection," Optics Letters, vol. 43, no. 14, pp. 3337-3340, 2018.

[18] Q. Wang, C. Du, J. Zhang, R. Lv, and Y. Zhao, "Sensitivityenhanced temperature sensor based on PDMS-coated long period fiber grating," Optics Communications, vol. 377, no. 15, pp. 89-93, 2016.

[19] F. Zou, Y. Liu, S. Zhu, C. Deng, Y. Dong, and T. Wang, "Temperature sensitivity enhancement of the nano-film coated long-period fiber gratings," IEEE Sensors Journal, vol. 16, no. 8, pp. 2460-2465, 2016.

[20] X. Dong, Z. Xie, C. Zhou, K. Yin, Z. Luo, and J. A. Duan, "Temperature sensitivity enhancement of platinum-nanoparticle-coated long period fiber gratings fabricated by femtosecond laser," Applied Optics, vol. 56, no. 23, pp. 6549-6553, 2017.

[21] J. Mohanraj, V. Velmurugan, S. Sathiyan, and S. Sivabalan, "All fiber-optic ultra-sensitive temperature sensor using fewlayer $\mathrm{MoS}_{2}$ coated D-shaped fiber," Optics Communications, vol. 406, no. 1, pp. 139-144, 2018.

[22] Y. Zhao, Y. Zhang, and R. Lv, "Simultaneous measurement of magnetic field and temperature based on magnetic fluidinfiltrated photonic crystal cavity," IEEE Transactions on Instrumentation and Measurement, vol. 64, no. 4, pp. 10551062, 2015.

[23] B. Sun, Z. Zhang, W. Wei et al., "Unique temperature dependence of selectively liquid-crystal-filled photonic crystal fibers," IEEE Photonics Technology Letters, vol. 28, no. 12, pp. 1282-1285, 2016.

[24] C. Colaco, P. Caldas, I. Del Villar, R. Chibante, and G. Rego, "Arc-induced long-period fiber gratings in the dispersion turning points," Journal of Lightwave Technology, vol. 34, no. 19, pp. 4584-4590, 2016.

[25] C. Zhang, W. Liao, K. Yang et al., "Fabrication of concave microlens arrays by local fictive temperature modification of fused silica," Optics Letters, vol. 42, no. 6, pp. 1093-1096, 2017. 